\title{
Effects of Soil Depths on Nymphal Eclosion of Melanoplus sanguinipes (Fabricius)
}

\author{
Alberto Pantoja*, ${ }^{*}$, Richard Ranft ${ }^{2}$, Dennis Fielding ${ }^{3}$, Aaron Hagerty $^{3}$ and Susan Emmert ${ }^{3}$ \\ ${ }^{1}$ United Nations Food and Agriculture Organization, Regional Office for Latin America and the Caribbean, Av. Dag \\ Hammarskjöld 3241, Vitacura, Santiago, Chile, USA \\ ${ }^{2}$ Department of Natural Resources, University of Alaska Fairbanks, Fairbanks, Alaska, USA \\ ${ }^{3}$ United States Department of Agriculture, Agricultural Research Service, Subarctic Agricultural Research Unit, Fair- \\ banks, Alaska, USA
}

\begin{abstract}
This work reports on the use of cultural practices that influence grasshoppers' nymphal emergence. Grasshopper eggs were buried at depths of $2,14,18,22$, and $26 \mathrm{~cm}$ in laboratory arenas. Nymph eclosion ranged from 77.5 to $87.8 \%$. However, nymph emergence, measured as the number of nymphs that reached the soil surface, was estimated at $70.9 \%$ when eggs were buried at $2 \mathrm{~cm}$, but was reduced to $2.5 \%$ at $18 \mathrm{~cm}$ depth. No nymphs emerged at depths of $22 \mathrm{~cm}$ or more. The relative high percentage of nymphal eclosion and the low or no nymph emergence suggests that the depths tested on this trial do not affect egg development and nymphal eclosion, but affect the ability of the insect to emerge to the soil surface, thus increasing first instar mortality. The addition of sand to the soil reduced nymphal emergence. A significantly lower percentage of hoppers emerged from sand as compared to soil, vermiculite, or soil mixed with 25, 50 and $75 \%$ sand. This suggests that cultural practices, such as plowing can be used as a management tool to control grasshoppers. Further research should investigate if nymphs died of suffocation at the eclosion site or in the process of emerging to the soil surface.
\end{abstract}

Keywords: Grasshoppers, cultural practices, soil.

\section{INTRODUCTION}

A large portion of the Alaskan cropland is enrolled under the Natural Resources Conservation Service, Conservation Reserve Program (CRP) land, for which most of it is located near Delta Junction to control wind erosion $[1,2]$. CRP land may harbor considerable populations of grasshoppers that often invade nearby crops [3]. Seven species of grasshoppers are common in Interior Alaska [4]. Three of the seven common species, Melanoplus borealis (Fieber), M. sanguinipes (Fabricius), and Camnula pellucida (Scudder), constitute a threat to crops $[4,5]$.

Considerable research has been conducted on grasshopper biology, ecology, competition, food quality, predators, pathogens, and population regulation of Alaska grasshoppers [6-12] but little work has been conducted on cultural practices (tillage, plowing) to manage grasshoppers in Interior Alaska. There is a lack of understanding of how cultural practices can affect egg mortality and nymphal emergence. Cultural practices like plowing can affect soil and ambient temperatures which may delay hatching, slow nymphal development or influence egg mortality [13]. The use of cultural practices is of particular importance in interior

*Address correspondence to this author at the United Nations Food and Agriculture Organization, Regional Office for Latin America and the Caribbean, Av. Dag Hammarskjöld 3241, Vitacura, Santiago, Chile, Room 319, USA; Tel: 56-2-923-2295; Fax: 56-2-923-2101;

E-mail: alberto.pantoja@fao.org
Alaska since it is expected that insect, diseases, and weed populations will increase with climate change [14]. Additionally, adaptation to northern environments has been demonstrated for high-latitude populations of grasshoppers [6$12]$. The ability to control grasshoppers with cultural practices and the development of integrated pest management (IPM) tactics will be a major step toward controlling grasshoppers in Alaska. This work reports on the use of simulated cultural practices to influence grasshoppers nymphal emergence. The identification of cultural control is of interest to organic growers in Alaska.

\section{MATERIALS AND METHODS}

\section{Burial Depths}

Through the course of this study, six trials were conducted to determine optimum burial depth to induce mortality of eggs or first instar nymphs of migratory grasshopper M. sanguinipes. Egg pods were obtained from Alaska and Idaho M. sanguinipes colonies maintained at the USDAARS Subarctic Agricultural Research Unit Grasshopper Laboratory [11]. In preliminary studies, egg pods were buried at various depths in soil columns to mimic field tillage depths as described below. Subsequently, egg pods were dissected and groups of ten eggs were selected based on apparent health and development. These egg groups (10 eggs per group) were then buried in soil columns at depths of 2 , $14,18,22$, and $26 \mathrm{~cm}$. Soil columns consisted of clear plastic tubes $(4.5 \mathrm{~cm}$ diam. x 14 or $30 \mathrm{~cm}$ long) filled with various 
amounts of 29GE01, Gerstle-Moosehead complex soil [15] obtained from the University of Alaska, Fairbanks, Delta Junction Field Research Site. Delta Junction soil was selected based on the presence and damage to crops of this species in the area [4]. Oviposition depth varies among grasshopper species from just under the surface to greater than $5 \mathrm{~cm}[16,17]$. In our study, we used two centimeters as control. Basal ends of the tubes were covered with nylon screening and secured with flexible polyurethane caps. Soil was poured loosely into the tubes to a depth of $3 \mathrm{~cm}$; then a $0.5 \mathrm{~cm}$ layer of moist vermiculite was placed over the eggs. Eggs were then covered with the appropriate amount of soil coverage $(2,14,18,22$ or $26 \mathrm{~cm}$ of soil). Apical ends of tubes were covered by nylon screening and secured with rubber bands. Soil columns were placed upright in a randomized block design with four replications per burial depth in two plastic tubs $(28.5 \times 40 \times 16.5 \mathrm{~cm})$ and supported with moist sand. The exterior of soil columns was covered with black plastic sheeting secured with rubber bands to reduce lateral lighting. Sand was kept moist and maintained at approximately 25 to $35 \%$ saturation using an ECH2O-10 dielectric aquameter (Decagon Devices Inc., Pullman WA).

On all trial arenas were conducted at ambient temperature on a bench top. Light was provided by a 45 watt incandescent light bulb suspended above the trial arena with 10 hours of light/ 14 hours dark cycles. Soil columns were monitored daily for emergence of first instar nymphs. Trials were terminated five days after nymphal emergence ceased in the $2 \mathrm{~cm}$ depth. At this stage, soil columns were inspected and the soil sieved to count the number of unhatched eggs and nymphs that did not reach the soil surface.

The proportion of emerged hoppers was calculated (number of hatched eggs/10) and transformed by the arcosine of the square root of the proportion before analysis. Zero and $100 \%$ counts were adjusted by the addition of 0.25 . The proportion of emerged grasshoppers from the Idaho and Alaska colonies was compared by using PROC TTEST with the Satterthwaite approximation for degrees of freedom [18, 19]. The effect of soil depth on nymphal eclosion was analyzed with PROC REG [18]. Several models were tested to determine the best fit.

\section{Soil Texture}

In a separate study, ten trials were conducted to determine the effect of soil texture on grasshopper emergence from a depth of $2 \mathrm{~cm}$. The research arenas and set up in the plastic columns and tubs with a randomized block design were the same as previously described. Six treatments using soil (29SC02, Salchaket very fine sandy soil) [16] and sand (Quikrete Premium Playsand No. 1113) were used to create treatments of soil with $0,25,50,75$, and $100 \%$ sand, and a sixth treatment of just vermiculite. Sand was tested as Alaska offers a great variability of soils textures $[1,15]$. Tubs were placed into a growth chamber with a setting of 10/14 day/night using florescent and incandescent lights, temperature range between 25 to $15^{\circ} \mathrm{C}, 70$ to $75 \%$ humidity. Moisture was kept within the same ranges as in the study before. Trials were terminated after five days after emergence ceased in the soil only treatment. The soil columns were then inspected for number of unhatched eggs and nymphs that did not reach the soil surface. Data on the number of emerged nymphs were subjected to analysis of variance and means separated by Turkeys test at the 5\% significance level. Data was transformed to arcosine of the square root of the proportion before analysis. Values presented in tables are actual percentages.

\section{RESULTS AND DISCUSSION}

The paired t-test indicated no significant $(\mathrm{F}=1.08, \mathrm{P}$ $0.7648, \mathrm{DF}=58 / 59$ ) between the numbers of nymph eclosed from the Idaho and Alaska colonies. Fielding [7-10] reported developmental adaptation between the two colonies. The differences in developmental parameters reported by Fielding [7-10] were associated with post-eclosion biological activities and were not detected in our study; therefore, we averaged nymphal developmental parameters over colony origin.

In general, nymphs began emerging from the $2 \mathrm{~cm}$ depth six days after trials were set up and all hoppers emerged by day 12 . Ninety percent of the nymphs emerged between days 6 to 9 . The overall mean nymphal eclosion was $82 \%$ with a range from 87.8 to $77.5 \%$, indicating that the trial arena provided an adequate environment to test nymphal emergence. Nymphal emergence, measured as the number of nymphs that reached the soil surface, was estimated at $70.9 \%$ for the $2 \mathrm{~cm}$ depth, but dropped to $2.5 \%$ for the $18 \mathrm{~cm}$ depth. Nymphal eclosion for the 22 and $26 \mathrm{~cm}$ depths was recorded at 77.5 and $82.5 \%$ respectively, but insects did not emerge to the soil surface (Table 1). The relative high percentage of nymphal eclosion and no emergence suggests that the depths tested on this trial do not affect egg development and nymphal eclosion, but affect the ability of the insect to emerge to the soil surface, thus increasing mortality of first instars. Additional studies are needed to identify the factors affecting nymphal mortality. In our study, we sifted the soil to collect dead insects, but the research arena was not designed to measure the depth at which nymphs died in the tube. Further

Table 1. Percentage of Nymphs Hatched and Nymphs Emerged at Different Soil Depths (n=24)

\begin{tabular}{|c|c|c|}
\hline Soil Depth (cm) & \% Nymphs Hatched & \% Nymphs Emerged \\
\hline \hline 2 & $87.8 \pm 3.0$ & $70.9 \pm 2.5$ \\
\hline 14 & $82.5 \pm 2.8$ & $7.5 \pm 2.8$ \\
\hline 18 & $81.3 \pm 3.2$ & $0 \pm \pm 1.8$ \\
\hline 22 & $77.5 \pm 3.8$ & $0 \pm$ \\
\hline 26 & $82.5 \pm 3.8$ & $0 \pm$ \\
\hline
\end{tabular}


research should investigate if nymphs died of suffocation at the eclosion site or in the process of emerging to the soil surface. Abrasion by soil particles and subsequent desiccation can be another explanation for nymph mortality.

Nymph mortality (nymphs hatched - nymphs emerged) for the $2 \mathrm{~cm}$ depth was recorded at $16.9 \%$ and increased to $78.8 \%$ for the $18 \mathrm{~cm}$ depth. This suggests that cultural practices, such as plowing can be used as management tool to control grasshoppers. No recent reports on the use of plowing to manage grasshopper could be found. In North Dakota, tillage to a depth of $11.4 \mathrm{~cm}$ provided up to $83 \% \mathrm{M}$. bivvitatus control [12]. No published reports on the use of cultural methods for grasshoppers control under Alaska cold soils conditions are available.

The relationship between nymphal emergence and soil depth is presented in Table 2, Fig. (1). In general, as the depth of soil increased, nymphal emergence decreased. The data show a quadratic relationship between nymphal emergence and soil depth. A significant $(\mathrm{P}<0.0001)$ decrease in nymphal emergence was found with each increase in soil depth. The expected percentage of nymphal emergence can be calculated with the regression model $\sum(y)=a+b x_{1}-c x^{2}$, where $y$ represents the expected nymphal emergence and $\mathrm{x}$ represents the soil depth (Fig. 1). The reduced nymphal emergence rate was associated to the inability of the nymphs to reach the soil surface after eclosion from the eggs (Table 1, 2, Fig. 1). In some instances, nymphs that reached the soil surface were found dead in the top of the research arena, suggesting that egg development is not affected at the depths tested, but successful nymphal emergence was reduced.

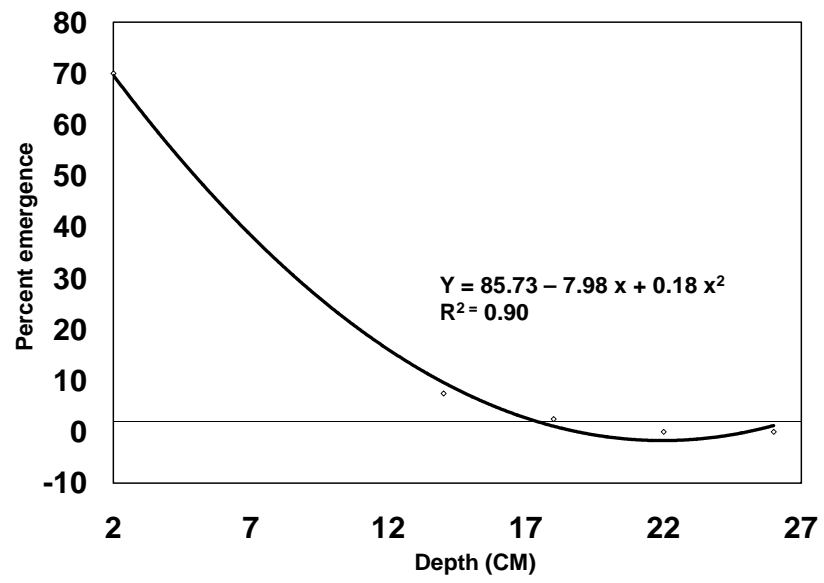

Fig. (1). Regression of nymphal emergence as affected by soil depth.

The substrate texture affected nymphal emergence (Fig. 2). A significantly lower percentage of hoppers emerged from sand as compared to soil, vermiculite, or soil mixed with 25,50 and $75 \%$ sand. However, nymphal emergence on soil with up to $25 \%$ sand was statistically equal to emergence from soil and vermiculite. Since all eggs were buried at the same depth, the data suggest that soils with more than 50\% sand reduced nymphal emergence (Fig 1). Similar to the solid depths experiment, some nymphs reached the surface of the research arena and died. Probably the coarse sand particles affected the insect cuticle during the emergence process. Additional research is needed to better

Table 2. Relationship between Nymphal Emergence and Soil Depth, Fitted model $\sum(\mathrm{y})=\mathbf{a}+\mathrm{bx}_{1}-\mathbf{c x}^{2} ; \mathbf{r}^{2}=\mathbf{0 . 9 0} \mathbf{C V}=\mathbf{5 8} ; \mathrm{X}=\mathbf{d e p t h}$ (cm)

\begin{tabular}{|c|c|c|c|c|}
\hline Parameter & Estimate & SE of Estimate & F Value & 35.63 \\
\hline \hline $\mathrm{a}$ & 85.73 & 2.41 & -20.65 & 0.0001 \\
\hline $\mathrm{b}$ & -7.98 & 0.386 & 13.27 & 0.0001 \\
\hline $\mathrm{c}$ & 0.18 & 0.014 & 0.0001 \\
\hline
\end{tabular}

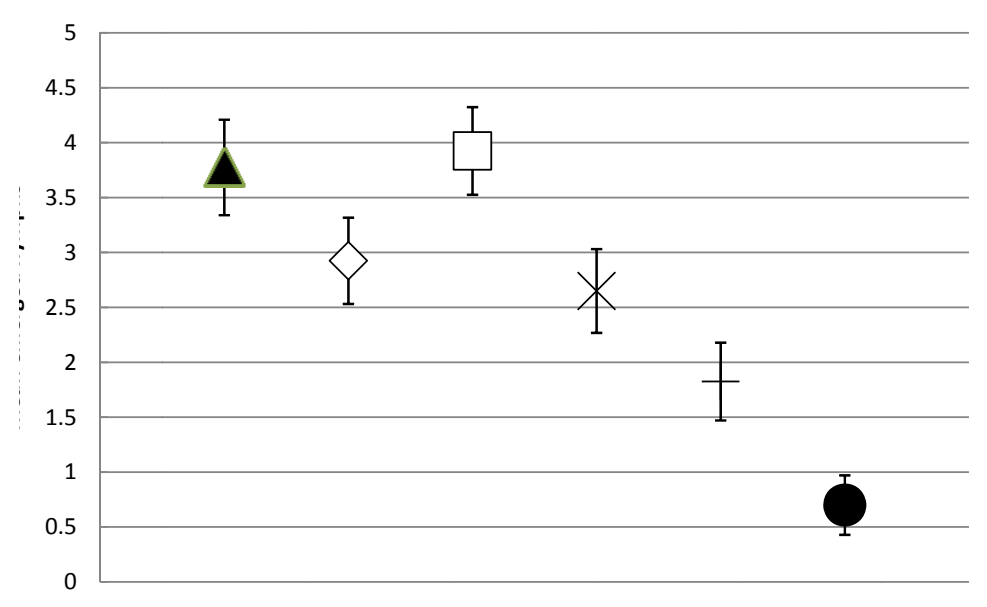

Fig. (2). Mean number of grasshoppers' nymphs emerged from five substrates (vermiculite (verm); soil; mixture of soil with 25, 50, and $100 \%$ sand). 
understand the effect of the substrate texture on first instar survival.

\section{ACKNOWLEDGEMENTS}

Technical support was provided by L. Defoliart, USDA, ARS Fairbanks.

\section{CONFLICT OF INTEREST}

None declared.

\section{REFERENCES}

[1] Schoephorster DB. Soil survey of Salcha-Big Delta area, Alaska. USDA - soil conservation service. Washington, DC: U.S. Government Printing Office 1973.

[2] Lewis CE, Franklin GD, Quarberg DM. Delta-clearwater lands opened for agriculture use: 2000 acre clearing; trial project. Agroborealis 1979; 11: 32-4.

[3] Gage SH, Mukerji MK. Crop losses associated with grasshoppers in relation to economics of crop production. J Econ Entomol 1978; 71: 487-98.

[4] Fielding DJ. Windowpane traps as a method of monitoring grasshopper (Orthoptera: Acrididae) populations in crops. J Kans Entomol Soc 2003; 76: 60-70.

[5] Begna SH, Fielding DJ. Response of barley to grasshopper defoliation in interior Alaska: dry matter and grain yield. J Econ Entomol 2005; 98: 1969-76.

[6] Fielding DJ. Intraspecific competition and spatial heterogeneity alter life history traits in an individual based modell of grasshoppers. Ecol Modell 2004a; 175: 169-87.
[7] Fielding DJ. Developmental time of Melanoplus sanguinipes F. (Orthoptera: Acrididae) at high latitudes. Environ Entomol 2004b; 33:1513-22.

[8] Fielding DJ. Optimal diapause strategies of a grasshopper, Melanoplus sanguinipes. J Insect Sci 2006; 6: 02. Available from: insectscience.org/6.02.

[9] Fielding DJ. Embryonic developmental rates of northern grasshoppers: implications for climate change and habitat management. Environ Entomol 2010; 39: 1643-51.

[10] Fielding DJ, DeFoliart LS. Density and temperature dependent melanization of fifth-instar Melanoplus sanguinipes: interpopulation comparisons. J Orthoptera Res 2005; 14:107-13.

[11] Fielding DJ, DeFoliart LS. Diapause traits of Melanoplus sanguinipes and $M$. borealis (Orthoptera: Acrididae). Ann Entomol Soc Am 2008; 101: 439-48.

[12] Fielding DJ, DeFoliart LS. Growth, development, and nutritional physiology of grasshoppers from temperate and subarctic regions. Physiol Biochem Zool 2007; 80: 607-18.

[13] Munro JA, Telford HS. Grasshopper control aided by tillage methods. Bulletin 1942; 309:14, [North Dakota Agricultural Experiment Station, Fargo, ND].

[14] Whitfield J. Too hot to handle. Nature 2003; 425: 338-9.

[15] Pink T. Soil survey of greater delta area, Alaska. Natural Resource Conservation Service 2008. [Accessed: April 18, 2012] Available from: http://soildatamart.nrcs.usda.gov/manuscripts/AK657/0/ Greater Delta. pdf.

[16] Onsager JA, Mulkern GB. Identification of eggs and egg-pods of North Dakota grasshoppers (Orthoptera: Acrididae). North Dakota Agric Exp Stn Bull 1963, 446: 1-48. [Fargo, North Dakota].

[17] Pfadt RE. Field guide to common western grasshoppers. Vol. 912. $3^{\text {rd }}$ ed. Laramie Wyoming, USA: Wyoming Agricultural Experiment Station Bulletin 2002.

[18] SAS. SAS 9.2 for windows. SAS institute. Carry North Carolina, USA 2008.

[19] Satterthwaite FW. An approximate distribution of estimates of variance components. Biometrics Bull 1946; 2: 110-14.

(C) Pantoja et al.; Licensee Bentham Open.

This is an open access article licensed under the terms of the Creative Commons Attribution Non-Commercial License (http://creativecommons.org/ licenses/by-nc/3.0/), which permits unrestricted, non-commercial use, distribution and reproduction in any medium, provided the work is properly cited. 